\title{
Preliminary report on the Ms 8.1 Kokoxili (Qinghai, China) earthquake of 14 November 2001
}

\author{
Center for Analysis and Prediction, China Seismological Bureau, P.O.Box 166, Beijing 100036, China
}

\begin{abstract}
An earthquake of magnitude 8.1 occurred on the remote high plateau of western China in the Kokoxili region near the Qinghai-Xinjiang border on 14 November, 2001. This event in the Kunlun Fault system is the largest earthquake that has occurred in China in the past 50 years. A preliminary report of the damage and surface rupture of this great Kokoxili earthquake is presented. The geological features, historical seismicity and earthquake monitoring capability in the earthquake area are reviewed. Implications of the aftershock activity and GPS data on the rupture mechanism are also discussed.
\end{abstract}

\section{Introduction}

A powerful earthquake of magnitude $\mathrm{M}_{\mathrm{s}} 8.1$ struck a remote and mountainous region in northwestern China on 14 November, 2001 at $5: 26 \mathrm{pm}$ (local time). This event had a focal depth of $15 \mathrm{~km}$, and it is the largest Chinese earthquake in the past 5 decades. The epicenter (at $36.2^{\circ} \mathrm{N}, 90.9^{\circ} \mathrm{E}$ ) is located in the Kokoxili region at an average elevation of $4000 \mathrm{~m}$ near the border between Qinghai Province and Xinjiang Uygur Autonomous Region.

The main shock is located along a western segment of the Kunlun Fault system near Buka Daban Feng, which at an elevation of $6,860 \mathrm{~m}$ is the highest summit of the Kunlun Range. The four strongest aftershocks occurred near Golmud, which is at $350 \mathrm{~km}$ to the east of the main shock. Spatial distribution of the aftershocks suggests that the Kokoxili earthquake may have ruptured a left-lateral strike-slip segment of the Kunlun fault system extending over several hundred kilometers.

\section{Earthquake Damage}

Located at the western edge of the Qaidam (Tsaidam) basin, Golmud is the second largest city of Qinghai Province. At a distance of $350 \mathrm{~km}$ to the east it is also the city nearest to the epicenter. Within and around Golmud buildings were shaken but no collapse was reported. Though the city government here oversees a total area of $124,500 \mathrm{~km}^{2}$, the urban center is localized in an area of $26 \mathrm{~km}^{2}$ at an elevation of $2780 \mathrm{~m}$, with 90,000 permanent residents and a nomadic population of 200,000 (at the end of 2000). Of the population in Golmud, $90.2 \%$ is Han people, while the other $9.8 \%$ belongs to other ethnic minorities.
In Mongolian Golmud means "a place with many rivers". The city has an abundance of natural resources including potassium, sodium, magnesium, lithium, boron, oil, gas, gold and precious stones. Its reserves of potassium, sodium, magnesium and lithium are the highest in China. Since 1980 Golmud's GDP has been increasing at a gross annual rate of $20.3 \%$ and by the year 2000 the GDP was over USD 1.5 billion.

Despite the severe weather as well as frequent earthquakes and landslides, a key railway system has been under construction here in the rugged terrain. Completed in the middle of 2001 the Xining-Golmud route is the highest railroad in the world, with a length of 816 $\mathrm{km}$ at an average elevation of 3,000 meters. This route links Golmud to Xining (the provincial capital of Qinghai). Construction of the second segment (the Qinghai-Tibet Railway) was initiated before the Kokoxili earthquake. This railway will connect Golmud with Lhasa, with a length of $1,118 \mathrm{~km}$ at an average elevation of 4,000 meters. The government will invest over US $\$ 3.1$ billion for the construction of the Qinghai-Tibet Railway, which is expected to be completed in 6 years.

Construction sites of the Qinghai-Tibet Railway are only 300 $\mathrm{km}$ away from the epicenter (Figure 1). Though few people live in the rugged region and no deaths or injuries were reported, a lot of work sheds were slit apart, some walls of the temporary houses for

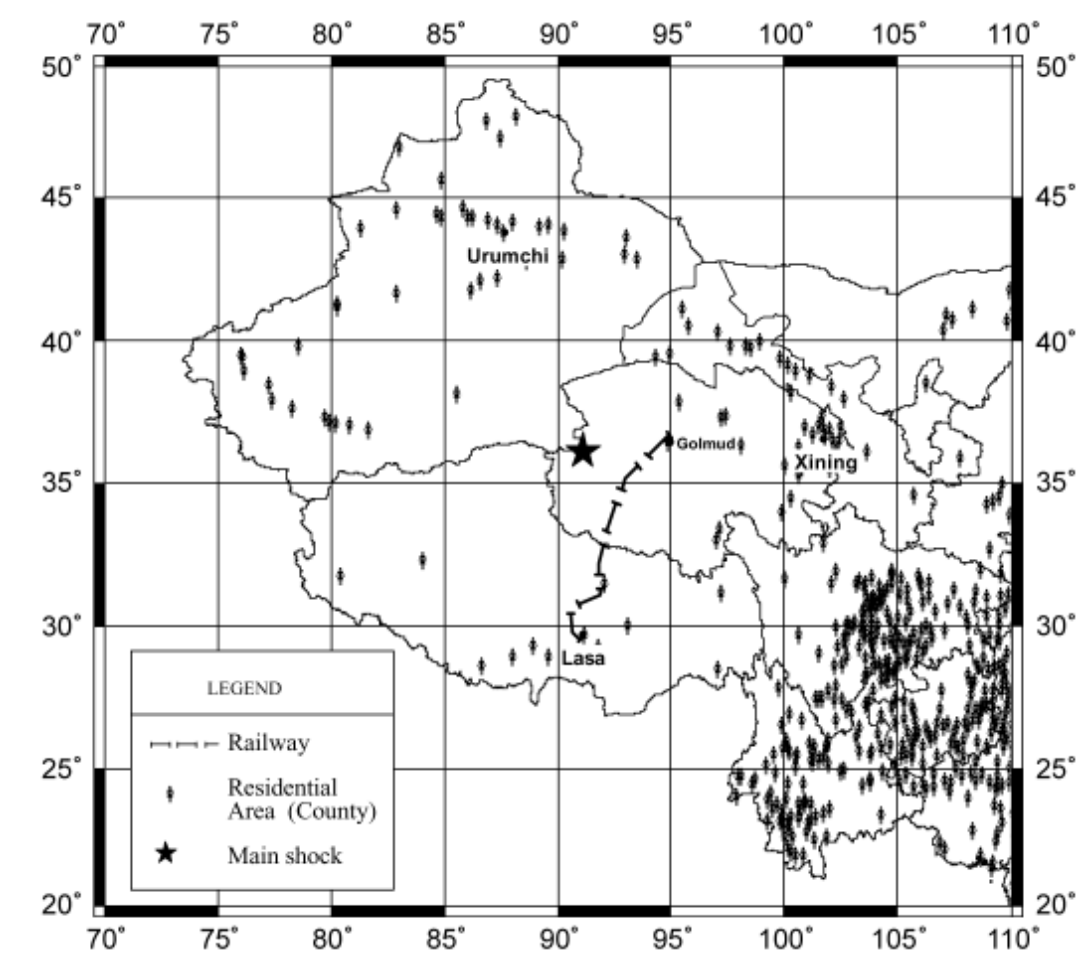

Figure 1 The sketch map of the Qinghai-Tibet Railway and the sparse distribution of residential areas (counties) in West China. 
workers were toppled, and a number of construction machines were buried. The tremor interrupted telecommunication among the construction sites. Projects in tunnels and on high-voltage cables were suspended, and the construction schedule had to be adjusted accordingly. The completed rail tracks will be carefully scrutinized for damage induced by the tremor.

Near the Qinghai-Tibet road, the walls of some houses were cracked. Figure 2 shows surface rupture features. A crevasse broke through the Qinghai-Tibet Road at the Kunlun pass at an elevation of $4,767 \mathrm{~m}$. At a few sites the ground was uplifted or fractured, and some landslides were observed. Horizontal offset up to $4 \mathrm{~m}$ was measured at a site less than $300 \mathrm{~km}$ from the epicenter.

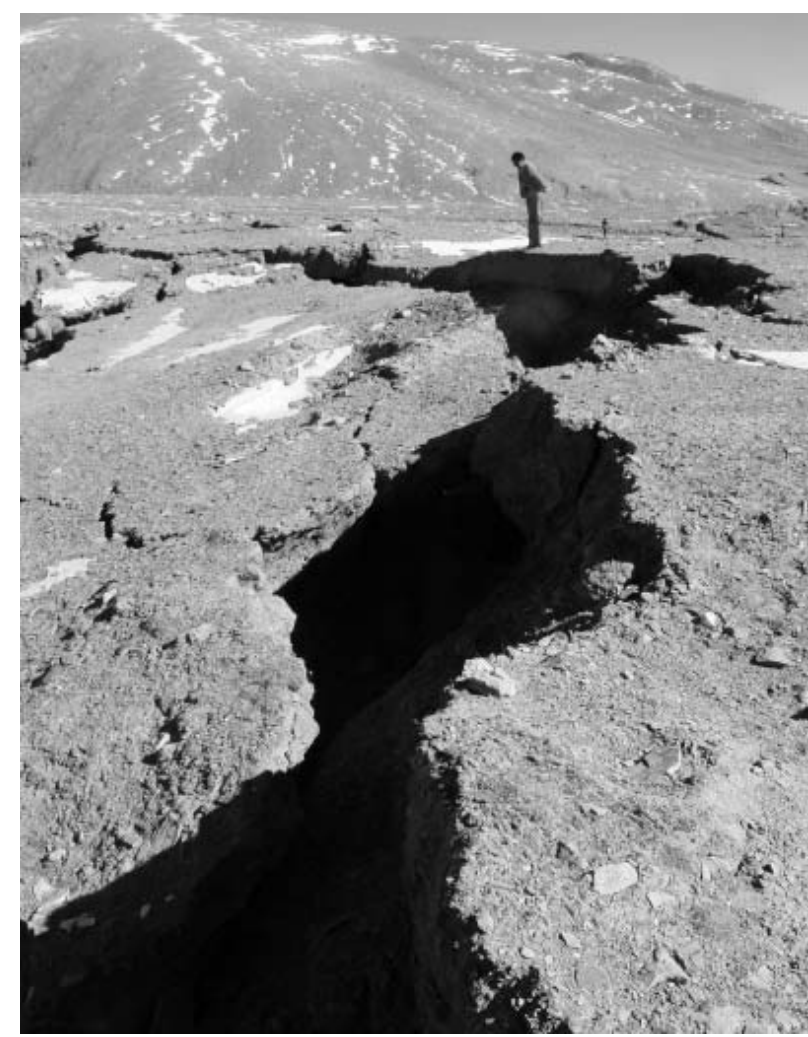

Figure 2 The grabens caused by the Ms8.1 earthquake at the east of the Kunlun Mountain Pass, with elevation over $4000 \mathrm{~m}$. (By the United Survey Group for Strong Earthquakes along the QinghaiTibet Railway, Nov. 20, 2001).

While the principal industry in Golmud is potash processing, the oil industry has also grown in importance. Several oil fields with substantial reserves are located in the extreme western end of the Qaidam Basin near Gasikule Lake about 450 kilometers west of Golmud. There were not any reports of evident damage to the petroleum plants in one month after the main shock had occurred. There are 3 missile bases in the Qaidam Basin (toward the north and northwest of Golmud). They were not appreciably impacted by the earthquake, because the ground damage primarily extended from the mountain pass toward the east. Nevertheless, the Kokoxili earthquake underscores the necessity of more robust reinforcement of structures in the vicinity of Golmud, to insure that important industrial centers and military bases can withstand the ground shaking from future strong earthquakes.

The Kokoxili region is famous for its Tibetan antelopes and harsh natural conditions. Before the tremor, wild-life protectors near the epicentral area had noticed some anomalous behaviors of wild animals. Two days before the main shock occurred, groups of wild animals were seen to migrate from the future epi- central area toward the east along the Qinghai-Tibet road. Several hours before the event, at the West Jinwulan Lake in the hinterland of Kokoxili, groups of wild yaks, wild Tibetan donkeys, Tibetan antelopes, wolves and foxes were seen scampering frantically as if some goblins were chasing them. Soon afterward the lake roared with a bang and billowed as high as 2 meters, and the water in some of the smaller lakes nearby seemed to be boiling, and then the tremor began.

\section{Historical seismicity and spatial clustering of earthquakes}

Suturing of a Late Cretaceous fold-and-thrust belt with a pre-Mesozoic continental plate resulted in the Kunlun Fault system, which is made up of large strike-slip faults that are aligned along the northern and eastern margins of the Tibetan Plateau in a roughly E-W direction. These left-lateral strike-slip strands are connected by shorter, oblique normal faults with a $\mathrm{N}$ to NE trend. The Kunlun faults are subparallel to the Qiman Tagh active thrusts to the north, which bound the southwestern edge of the Qaidam (Tsaidam) Basin (Chen et al., 1999; Van der Woerd, 2000).

Aftershocks of the great Kokoxili earthquake provide some constraints on the faulting style and spatial extent of the rupture. Table 1 compiles the data for 5 large aftershocks located by seismic networks of the China Seismological Bureau. Except for the 30 November event (which occurred near the main shock), the four largest aftershocks were all located near Golmud to the east of the main shock. Such a spatial distribution of aftershocks indicates that the earthquake may have ruptured a strike-slip segment of the Kunlun fault system, which extends more than $200 \mathrm{~km}$ from Buka Daban Feng to the Kunlun pass.

Including the Kokoxili event, 14 earthquakes with $\mathrm{M}_{\mathrm{S}}$ $\geq 7.0$ have occurred in the past 100 years within a relatively small region (of $30-40^{\circ} \mathrm{N}, 80-100^{\circ} \mathrm{E}$ ) (Table 2). Due to the sparse population and the harsh natural conditions in this region near the Kunlun Range, fewer than 350 fatalities have resulted from the 14 strong earthquakes. The houses and structures are not very elaborate and therefore the seismic damage can be repaired readily once agricultural production has been restored after a tremor.

Historically the strike-slip faults of the Kunlun system have been very active. As shown in Table 2 two major earthquakes occurred near Dulan in 1937 and 1963. In the latter event, the north side slipped westward relative to the south side by around 8 meters. It should be noted that in the past 50 year all 6 strong events have aligned themselves along the northern margin of the Tibetan Plateau. The last 4 strong earthquakes in this region occurred in 1963 (with $\mathrm{M}_{\mathrm{s}}$ 7.0), 1973 (with $\mathrm{M}_{\mathrm{s}} 7.3$ ), 1997 (with $\mathrm{M}_{\mathrm{s}} 7.5$ ) and 2001 (with $M_{s} 8.1$ ). These recent events are all clustered at latitudes around

Table 1 The 14 November, 2001 earthquake and the major aftershocks within 1 month after the main event.

\begin{tabular}{|c|c|c|c|}
\hline Date and local time & Location & Magnitude (Ms) & Remark \\
\hline $2001-11-14$ 17:32 & $90.9^{\circ} \mathrm{E}, 36.2^{\circ} \mathrm{N}$ & 8.1 & Main shock \\
\hline 2001-11-15 07:05 & $94.7^{\circ} \mathrm{E}, 35.6^{\circ} \mathrm{N}$ & 5.3 & Near Golmud \\
\hline 2001-11-19 05:59 & $94.0^{\circ} \mathrm{E}, 35.9^{\circ} \mathrm{N}$ & 5.7 & Near Golmud \\
\hline $2001-11-2001: 45$ & $93.8^{\circ} \mathrm{E}, 35.8^{\circ} \mathrm{N}$ & 5.6 & Near Golmud \\
\hline $2001-11-3018: 43$ & $90.9^{\circ} \mathrm{E}, 36.1^{\circ} \mathrm{N}$ & 5.1 & Near main shock \\
\hline $2001-12-08$ 12:12 & $93.3^{\circ} \mathrm{E}, 36.0^{\circ} \mathrm{N}$ & 5.4 & Near Golmud \\
\hline
\end{tabular}




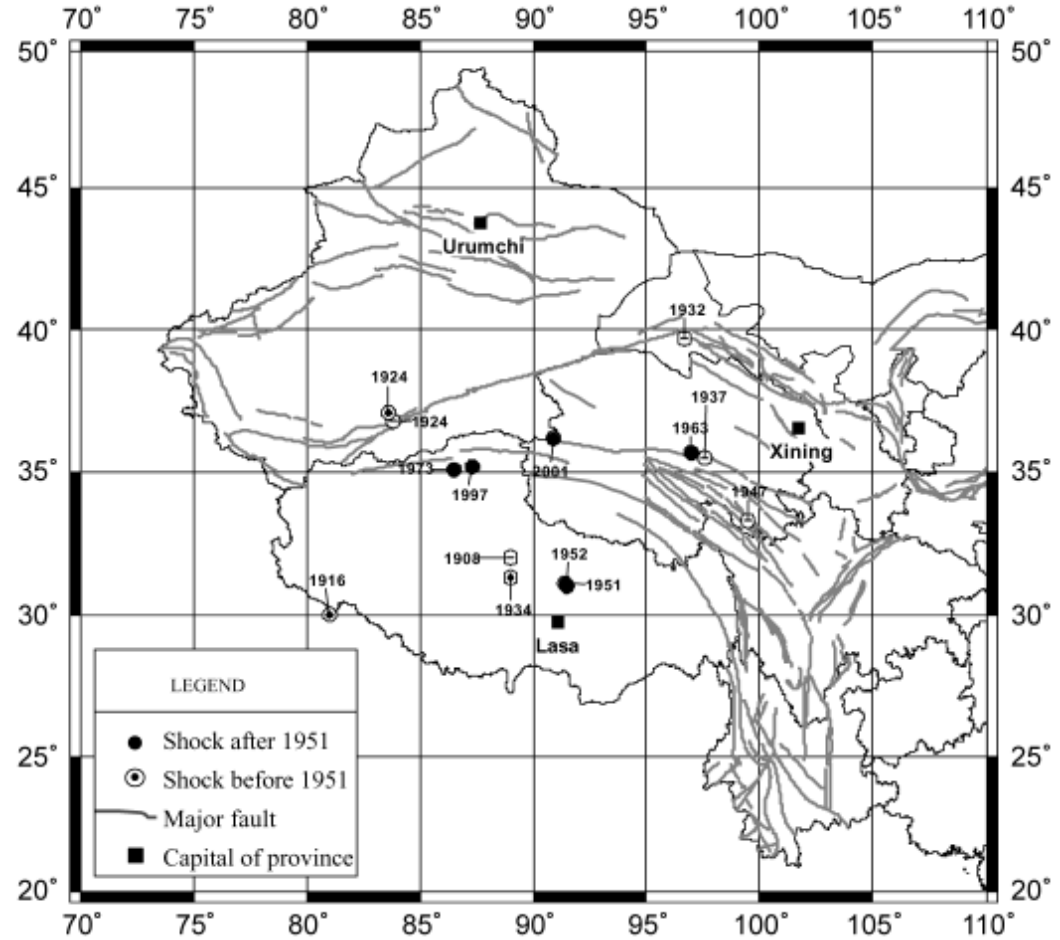

Figure 3 Sketch map of west China with Quaternary active faults and $M_{s} \geq .0$ earthquakes after 1900.

$35.5^{\circ} \mathrm{N}$ (Figure 3 and Table 2), indicating that this may represent an area of localized stress concentration and seismic instability.

It seems that the spatial and temporal clustering trends are correlated. Only 4 years ago, the Manyi earthquake (Ms 7.5, November 1997) ruptured a nearby left-lateral fault of the Kunlun fault system, at a location about $300 \mathrm{~km}$ to the west of the Kokoxili epicenter. These two large earthquakes have comparable magnitudes, and SAR interferometry indicates that the surface rupture of the Manyi earth- quake extended over $170 \mathrm{~km}$ with $7 \mathrm{~m}$ of slip (Peltzer et al., 1999). This phenomenon of spatio-temporal clustering manifested by the 1997 Manyi and 2001 Kokoxili earthquakes might arise from Coulomb stress triggering.

\section{Focal Mechanism and Earthquake Monitoring Capability}

Since 1966 the China Seismological Bureau has undertaken a continuous effort to expand and improve seismic monitoring stations and precursor observatories in western China, especially in earthquake-prone areas even if they are sparsely populated. The facilities at stations administered by the Precursor Observation Network of China have been recalibrated or upgraded with digital components before 2000. By the end of 2001, there are 33 permanent stations in west China (west of $100^{\circ} \mathrm{E}$ and north of $30^{\circ} \mathrm{N}$ ) newly installed with digital and analog equipments that continuously monitor seismic, magnetotelluric, hydrological, geochemical, gravity and ground tilt signals. Among the 33 stations, 29 concentrate on seismic measurements, 13 on geomagnetic signals, 11 on crustal deformation (with tiltmeters) and several stations focus on geochemical analyses, electrical resistivity and other precursory signals. The nearest station to the Kokoxili earthquake was located at Golmud, which monitors seismic, geomagnetic and hydrologic signals. No obvious anomalies or precursors were reported before this great earthquake and any of its aftershocks.

There are also local seismic networks jointly managed by the provincial seismological bureaus and China Seismological Bureau. In the vicinity of the Kokoxili region, there are 4 local seismic monitoring networks in the provinces of Sichuan, Yunnan, Gansu and

Table 2 Strong earthquakes in the vicinity of the Kunlun Range (1900-2001).

\begin{tabular}{|c|c|c|c|c|c|}
\hline & Date & Location & Place Name & Ms & Hazards \\
\hline 1 & $1908-08-20$ & $89.0^{\circ} \mathrm{E}, 32.0^{\circ}$ & NQilin Lake, Tibet & 7.0 & 1 \\
\hline 2 & $1916-08-28$ & $81.0^{\circ} \mathrm{E}, 30.0^{\circ}$ & \begin{tabular}{l|l}
$\mathrm{N}$ & South of Pulan, Tibet
\end{tabular} & 7.5 & 1 \\
\hline 3 & 1924-07-03 & $83.8^{\circ} \mathrm{E}, 36.8^{\circ}$ & $\mathrm{N} \mid$ East of Minfeng, Xinjiang & 7.3 & $\begin{array}{l}\text { Over } 100 \text { persons and about } \\
5000 \text { sheep were killed }\end{array}$ \\
\hline 4 & $1924-07-12$ & $83.6^{\circ} \mathrm{E}, 37.1^{\circ}$ & $\mathrm{N}$ East of Minfeng, Xinjiang & 7.2 & 1 \\
\hline 5 & $1932-12-25$ & $96.7^{\circ} \mathrm{E}, 39.7^{\circ}$ & N Yumen-Changma, Gansu & 7.6 & $\begin{array}{l}270 \text { were killed and } 300 \\
\text { were injured }\end{array}$ \\
\hline 6 & 1934-12-15 & $89.0^{\circ} \mathrm{E}, 31.3^{\circ}$ & N North-east of Shenzha, Tibet & 7.0 & 1 \\
\hline 7 & 1937-01-07 & $97.6^{\circ} \mathrm{E}, 35.5^{\circ}$ & N East of Alan Lake, Qinghai & 7.5 & $\begin{array}{l}2 \text { person and } 200 \text { domestic } \\
\text { animals were killed }\end{array}$ \\
\hline 8 & 1947-03-17 & $99.5^{\circ} \mathrm{E}, 33.3^{\circ}$ & N South of Dari, Qinghai & 7.7 & 1 \\
\hline 9 & 1951-11-18 & $91.4^{\circ} \mathrm{E}, 31.1^{\circ}$ & $\mathrm{N}$ Dangxiong, Tibet & 8.0 & I \\
\hline 10 & 1952-08-08 & $91.5^{\circ} \mathrm{E}, 31.0^{\circ}$ & \begin{tabular}{l|l|}
$\mathrm{N}$ & Northeast of Dangxiong, Tibet
\end{tabular} & 7.5 & 54 persons were killed \\
\hline 11 & 1963-04-19 & $97.0^{\circ} \mathrm{E}, 35.7^{\circ}$ & NAlan Lake, Qinghai & 7.0 & I \\
\hline 12 & 1973-07-14 & $86.5^{\circ} \mathrm{E}, 35.1^{\circ}$ & \begin{tabular}{l|l}
$\mathrm{N}$ & Yiji Taicuo, Tibet \\
\end{tabular} & 7.3 & 1 \\
\hline 13 & $1997-11-08$ & $87.3^{\circ} \mathrm{E}, 35.2^{\circ}$ & \begin{tabular}{l|l}
$\mathrm{N}$ & Manyi, Tibet \\
\end{tabular} & 7.5 & 1 \\
\hline 14 & 2001-11-14 & $90.9^{\circ} \mathrm{E}, 36.2^{\circ}$ & \begin{tabular}{l|l}
$N$ & $\begin{array}{l}\text { Kunlun Mountain at the Border } \\
\text { of Qinghai and Xinjiang }\end{array}$
\end{tabular} & 8.1 & 1 \\
\hline
\end{tabular}


Table 3 Earthquake parameters determined by different sources (collected by Zheng Sihua).

\begin{tabular}{c|c|c|c|c}
\hline & $\begin{array}{c}\text { US } \\
\text { Geological } \\
\text { Survey }\end{array}$ & Harvard CMT & $\begin{array}{c}\text { Earthquake } \\
\text { Research Institute, } \\
\text { U. of Tokyo }\end{array}$ & $\begin{array}{c}\text { Center of China } \\
\text { Digital Seismic } \\
\text { Network }\end{array}$ \\
\hline $\mathbf{M}_{\mathbf{0}}$ & $3.5 \times 10^{20} \mathrm{Nm}$ & $5.8 \times 10^{20} \mathrm{Nm}$ & $3.9 \times 10^{20} \mathrm{Nm}$ & $2.2 \times 10^{20} \mathrm{Nm}$ \\
\hline $\boldsymbol{M}_{\boldsymbol{w}}$ & 7.7 & 7.8 & 7.7 & 7.5 \\
\hline Nodal Plane 1 & $32 / 4 /-76$ & $95 / 54 /-7$ & $89 / 98 /-2$ & $273 / 11 /-140$ \\
\hline Nodal Plane 2 & $198 / 86 /-91$ & $190 / 84 /-144$ & & $144 / 83 /-81$ \\
\hline Epicenter & $90.504^{\circ} \mathrm{E}$ & $92.35^{\circ} \mathrm{E}$ & $90.50^{\circ} \mathrm{E}$ & $\begin{array}{c}90.80^{\circ} \mathrm{E} \\
36.58^{\circ} \mathrm{N}\end{array}$ \\
\hline Depth & $56.014^{\circ} \mathrm{N}$ & $35.54^{\circ} \mathrm{N}$ & $36.01^{\circ} \mathrm{N}$ & $22 \mathrm{~km}$ \\
\hline Data from & $\mathrm{GSN}$ & $15 \mathrm{~km}$ & $20 \mathrm{~km}$ & $\mathrm{GSN}$ \\
\hline Stations used & 33 & $\mathrm{GSN}$ & 21 & 22 \\
\hline Data used & $\begin{array}{c}3 \text { components of } \\
\text { body waves }\end{array}$ & $\begin{array}{c}3 \text { components of } \\
\text { surface waves }\end{array}$ & $\begin{array}{c}\text { Vertical component } \\
\text { of P wave }\end{array}$ & $\begin{array}{c}3 \text { components of } \\
\text { body waves }\end{array}$ \\
\hline Period used & $\sim 300 \mathrm{~s}$ & $\sim 300 \mathrm{~s}$ & $\sim 300 \mathrm{~s}$ & $45-100 \mathrm{~s}$ \\
\hline
\end{tabular}

Xinjiang. The Chengdu, Kunming, Lanzhou and Urumqi Seismic Networks have $18,23,18$, and 20 seismic stations, respectively. While these stations are all equipped with 3-component seismometers and provide good coverage within each province, none of them is located within a radius of $1,000 \mathrm{~km}$ from the main event and its aftershocks. The nearest station of the China Digital Seismograph Network (CDSN) is at Golmud (at an elevation around 3,000 m), which is the only seismic station within $500 \mathrm{~km}$ from the epicenter that provided digital earthquake records. Therefore the detection power for earthquakes near the epicenter was quite low, with a magnitude threshold greater than $\mathrm{M}_{\mathrm{s}} 4.0$.

Due to the sparse and asymmetrical distribution of seismic stations, determination of the focal mechanisms of the Kokoxili earthquake series is subject to much uncertainty. Source parameters for the main event and 5 aftershocks determined by the USGS, Harvard CMT, ERI (University of Tokyo) and Center of CDSN (CCDSN) are compared in Table 3. Discrepancies exist not only in location of the main event and its aftershocks, but also in focal mechanism, seismic moment and focal depth. USGS used 3 components of body waves recorded by 33 stations of Global Seismic Network (GSN) with periods around 300s, while the Harvard CMT used surface waves from 48 GSN stations around 300s. While some of the apparent discrepancies can be attributed to different data sources, a more definitive interpretation of the rupture process would require further geological and geophysical investigations that are currently in progress.

\section{GPS observations}

To provide high-resolution data for earthquake research, crustal deformation in China has been measured extensively by GPS, VLBI and SLR. Since the end of 2000 the Crustal Movement Observation Net- work of China (CMONOC) has been fully operational. The network includes 25 permanent GPS sites, 56 sites that are resurveyed annually, and over 1,000 sites to be surveyed on a decadal basis. Within a radial distance of $1,500 \mathrm{~km}$ from the epicenter of the Kokoxili earthquake, there are 9 permanent GPS sites (Figure 4 and Table 4). The nearest one to the main shock is DLHA in Delinha county, Qinghai province. The aftershocks near Golmud (Table 1) took place between the main shock and DLHA.

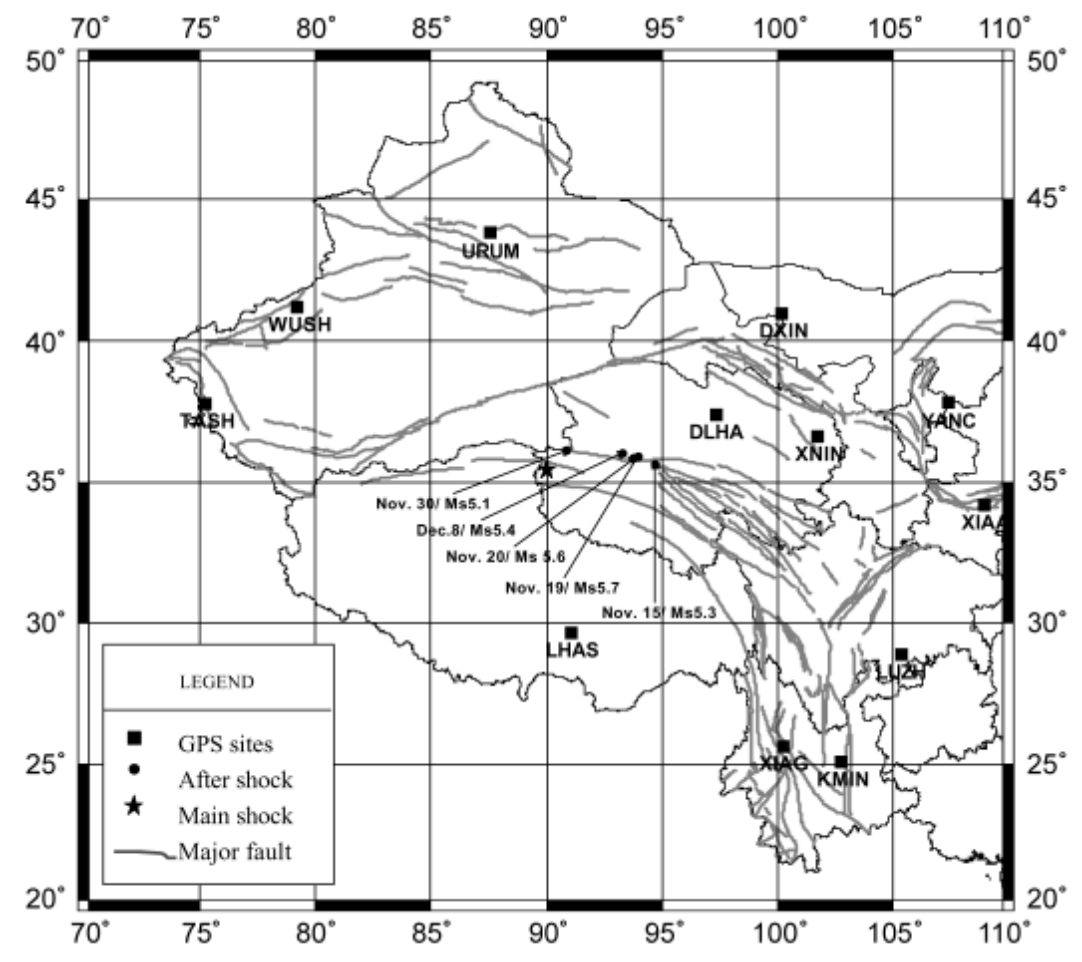

Figure 4 The permanent GPS sites in west China and the earthquakes related to the mainshock on Nov.11 2001. 
Table 4 Distance between the GPS sites and the series of shocks.

\begin{tabular}{c|c|c|c|c|c|c|c}
\hline \multicolumn{2}{l}{ GPS Station } & \multicolumn{5}{c}{ Distance $(\mathbf{k m})$ between each GPS Station and } \\
\multicolumn{2}{l|}{ the epicenter of 2001 Earthquakes } \\
\hline Code & Name & Nov.14 & Nov.15 & Nov.19 & Nov.20 & Nov.30 & Dec.8 \\
\hline DLHA & Delingha, Qinghai & 592 & 311 & 344 & 365 & 595 & 395 \\
\hline LHAS & Lhasa, Tibet & 728 & 742 & 746 & 729 & 717 & 735 \\
\hline URUM & Urumqi, Xinjiang & 892 & 1097 & 1036 & 1037 & 903 & 996 \\
\hline DXIN & Dingxin, Gansu & 968 & 767 & 782 & 802 & 974 & 817 \\
\hline XNIN & Xining, Qinghai & 974 & 645 & 702 & 721 & 976 & 763 \\
\hline WUSH & Wushi, Xinjiang & 1157 & 1485 & 1414 & 1404 & 1163 & 1353 \\
\hline TASH & Tashikuergan, Xinjiang & 1403 & 1752 & 1682 & 1667 & 1405 & 1618 \\
\hline XIAG & Xiaguan, Yunnan & 1477 & 1232 & 1291 & 1291 & 1469 & 1333 \\
\hline YANC & Yanchi, Ningxia & 1479 & 1162 & 1214 & 1235 & 1481 & 1273 \\
\hline LUZH & Luzhou, Yunnan & 1585 & 1255 & 1326 & 1335 & 1580 & 1385 \\
\hline XIAA & Xi'an, Shanxi & 1659 & 1313 & 1378 & 1396 & 1658 & 1442 \\
\hline KMIN & Kunming, Yunnan & 1684 & 1409 & 1474 & 1476 & 1676 & 1522 \\
\hline
\end{tabular}

DLHA GPS
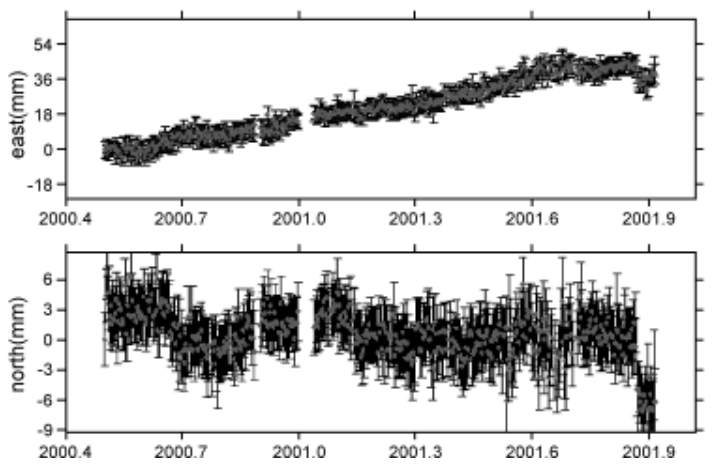

LHAS GPS
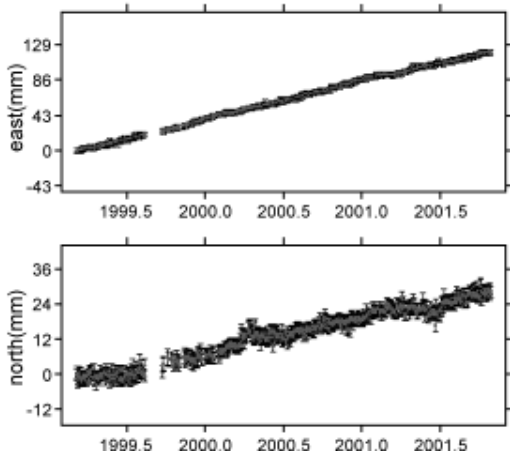

URUM GPS
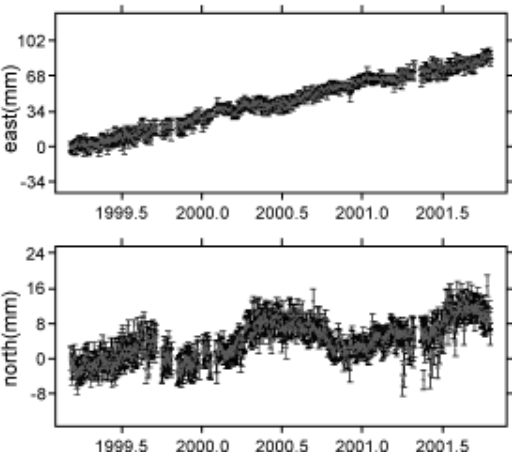

Figure 5 Horizontal motions recorded by a GPS site near Delingha, Lhasa and Urumqi, which are the 3 nearest GPS stations to the M8.1 main shock. (From Crustal Movement Observation Network of China).

GPS data recorded at DLHA indicate a relative shortening with respect to the epicenter both in the east and north direction right after the $\mathrm{M}_{\mathrm{s}} 8.1$ event (Figure 5). In contrast, no obvious changes were displayed at LHAS and URUM, which are about 700-900 km away from the epicenter. The monitoring is continued and new data are being processed to provide insight into crustal deformation in the Kokoxili region.

\section{Acknowledgements}

We are grateful to Mr. Lu Ming from China Seismological Bureau, Mr. Sun Hanrong from Crustal Movement Observation Network of China (CMONOC), Dr. Zheng Sihuan and Dr. Tian Qinjian who provided the GPS data, source mechanism, and geological background, respectively. We thank Professor Teng-fong Wong (of State University of New York at Stony Brook) for reviewing the manuscript.

\section{References}

Chen, W.-P., Chen, C.-Y, and Nabelek, J. L., 1999, Present-day deformation of the Qaidam basin with implications for intra-continental tectonics, Tectonophysics, 305, 165-181.

Peltzer, G., Crampe, F., and King, G., 1999, Evidence of nonlinear elasticity of the crust from the Mw7.6 Manyi (Tibet) earthquake, Science, 286, $272-276$,

Van de Woerd, J., Ryerson, F. J., Tapponnier, P., Meriaux, A.-S., Gaudemer, Y., Meyer, B., Finkel, R. C., Caffee, M. W, Zhao, G., and Xu, Z., 2000, Uniform slip-rate along the Kunlun Fault: Implications for seismic behaviour and large-scale tectonics, Geophys. Res. Lett., 27, 2353-2356.
Dr. Li Li, born in 1969, assistant professor in geophysics, just finished her 2-year P. PHD work from the Geology and Geophysics Institute of Chinese Academy of Sciences. She has been working at strong continental earthquakes, stress field and its simulation for earthquake process, water pore pressure and its influence on seismicity, and seismic risk assessment.

Chen Yong, born in 1942, professor in geophysics, member of the Chinese Academy of Sciences and of the Third World Academy of Sciences, has worked on rock physics under high temperature and high pressure, seismic hazard and risk assessment, fractal analysis of seismicity and chaotic modeling and seismic tomography. He developed a new methodology and combining the World Seismic Hazard and Risk Maps by combining seismology, engineering and social sciences and found pattern characteristics of foreshocks and proposed the concept of physical fractal.
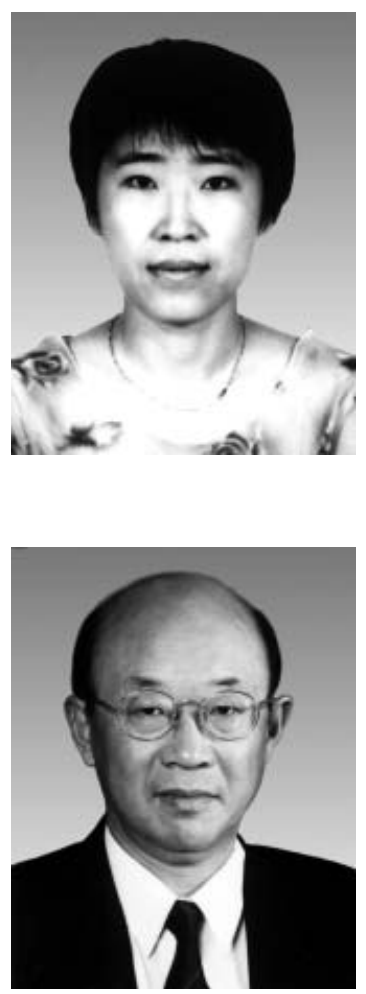